\title{
Natural hybridization between Atlantic salmon, Salmo salar, and brown trout, Salmo trutta, in northern Spain
}

\author{
C. Garcia de Leaniz and E. Verspoor \\ Department of Agriculture and Fisheries for Scotland, Marine Laboratory, Victoria Road, \\ Aberdeen $A B 98 D B, U . K$.
}

(Received 25 April 1988, Accepted 28 July 1988)

\begin{abstract}
Hybrids between Atlantic salmon and brown trout were detected in two of four watersheds studied in northern Spain. The proportions of hybrids in samples of 'salmon ' ranged from 0 to $7.7 \%$ but they were not significantly heterogeneous among locations, resulting in a mean hybridization rate of $2 \cdot 3 \%$. This is the highest rate of natural hybridization so far reported and is significantly greater than rates observed elsewhere in Europe.
\end{abstract}

\section{INTRODUCTION}

Hybridization between Atlantic salmon, Salmo salar L., and brown trout, S. trutta L., appears widespread (Solomon \& Child, 1978; Beland et al., 1981; Crozier, 1984; Verspoor, 1988) though observed rates vary from region to region. The reasons for this are not clear. Hubbs (1955) predicted that hybridization will be higher where one species is introduced or where the environment of the species involved has been physically or biologically disturbed. Reported here are hybridization rates between Atlantic salmon and brown trout from rivers in northern Spain, where the two species coexist at the southern limit of their endemic distribution in western Europe.

\section{METHODS AND MATERIALS}

Electrofishing during September and October 1987 was used to collect 169 ' salmon ' parr from eight locations in four watersheds in northern Spain (Fig. 1) where Atlantic salmon and brown trout coexist. These watersheds have in recent years accounted for $c .30 \%$ of the total Spanish salmon catch (Garcia de Leaniz \& Martinez, 1988). The fish were then frozen for protein analysis. Six smolts captured by local biologists in 1985 from the R. Sella were also examined, giving a total sample of 175 fish.

Hybrids were identified using the diagnostic electrophoretic banding patterns of glucose phosphate isomerase (GPI) and phosphoglucomutase (PGM) as described by Verspoor (1988). All $G$ tests have incorporated William's correction for small expected frequencies (Sokal \& Rohlf, 1981).

\section{RESULTS}

Atlantic salmon $\times$ brown trout hybrids were detected in two of the four watersheds sampled (Table I). In the Ason watershed, hybrids were found in both samples collected, while those in the R. Pas were found only in the sample from the higher reaches (Fig. 1). The two smallest hybrids, from the R. Pas, were very similar or identical to salmon parr in external appearance, while those from the 


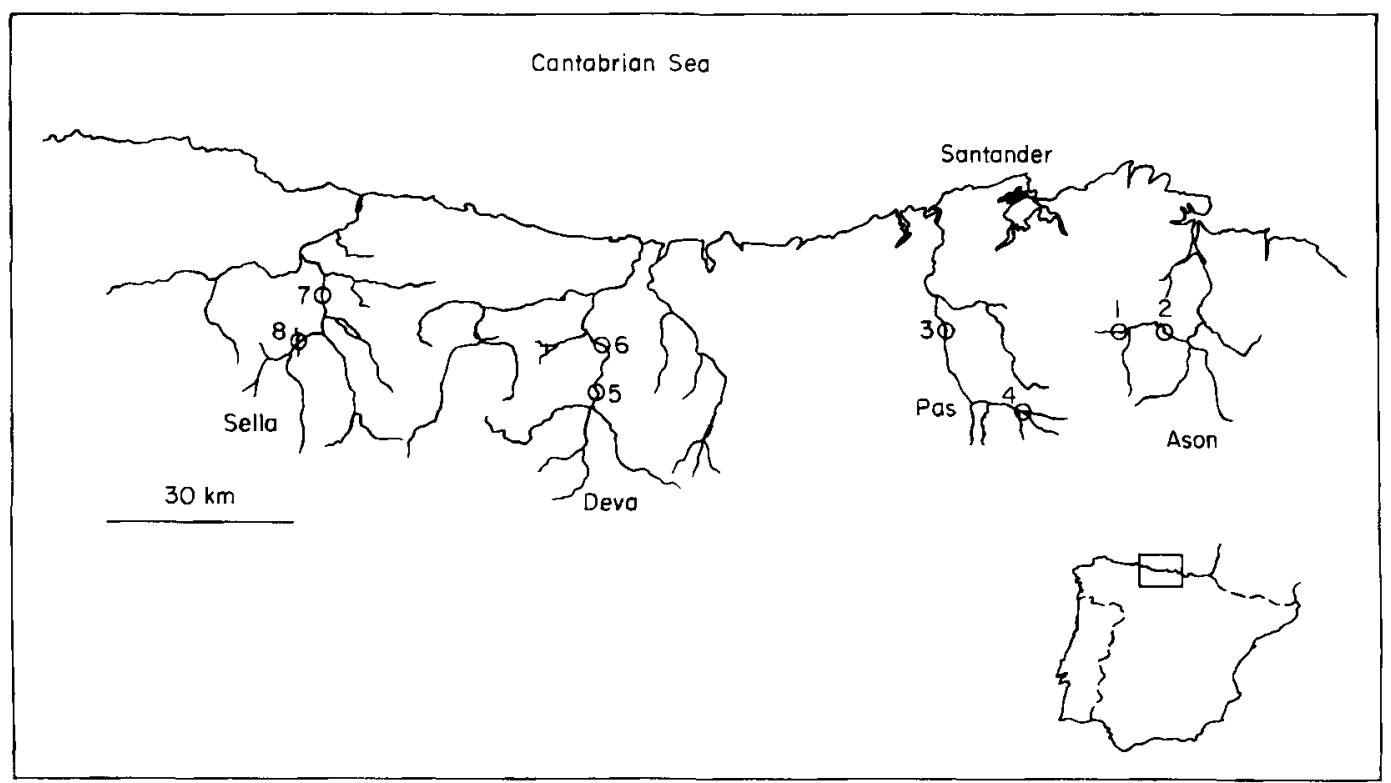

FIG. 1. Location of watersheds and sites sampled in northern Spain. Sampling site numbers refer to Table I.

TABLE I. Observed incidence of Atlantic salmon $\times$ brown trout hybrids in samples of 'salmon' from rivers in northern Spain. Sampling site numbers correspond to Fig. 1

\begin{tabular}{|c|c|c|c|c|}
\hline \multirow{2}{*}{$\begin{array}{l}\text { Watershed/ } \\
\text { sampling site }\end{array}$} & \multirow{2}{*}{$\begin{array}{l}\text { Number of } \\
\text { 'salmon' }\end{array}$} & \multicolumn{2}{|c|}{ Hybrids } & \multirow{2}{*}{$\begin{array}{l}\text { Observed brown trout/ } \\
\text { salmon ratio during } \\
\text { electrofishing } \dagger\end{array}$} \\
\hline & & No. & $\%$ & \\
\hline Rio Ason & & & & $259 / 55^{* * *}$ \\
\hline 1. Bustablado & 29 & 1 & $3 \cdot 4$ & \\
\hline 2. Valle & 28 & 1 & $3 \cdot 6$ & \\
\hline Rio Pas & & & & $14 / 63 * * *$ \\
\hline 3. Soto de Iruz & 39 & 0 & 0 & \\
\hline 4. Riolangos & 26 & 2 & $7 \cdot 7$ & \\
\hline Rio Deva & & & & $29 / 10^{* *}$ \\
\hline 5. Ojedo & 1 & 0 & 0 & \\
\hline 6. Lebeña & 9 & 0 & 0 & \\
\hline Rio Sella & & & & $66 / 37^{* *}$ \\
\hline 7. Millares (parr) & 6 & $\mathbf{0}$ & 0 & \\
\hline (smolts) & 6 & 0 & 0 & \\
\hline 8. Ponga & 31 & 0 & 0 & \\
\hline Total & 175 & 4 & $2 \cdot 3$ & $368 / 165^{* * *}$ \\
\hline
\end{tabular}

†Chi-square, ${ }^{* *} P<0.01,{ }^{* * *} P<0.001$.

Ason watershed were larger and visually more intermediate, one resembling a salmon [Fig. 2(b)], and the other a brown trout [Fig. 2 (d)].

The incidence of hybrids ranged from 0 to $7 \cdot 7 \%$ among sampling sites (Table I), but these values were not significantly heterogeneous $(2 \times 4$ contingency table; 


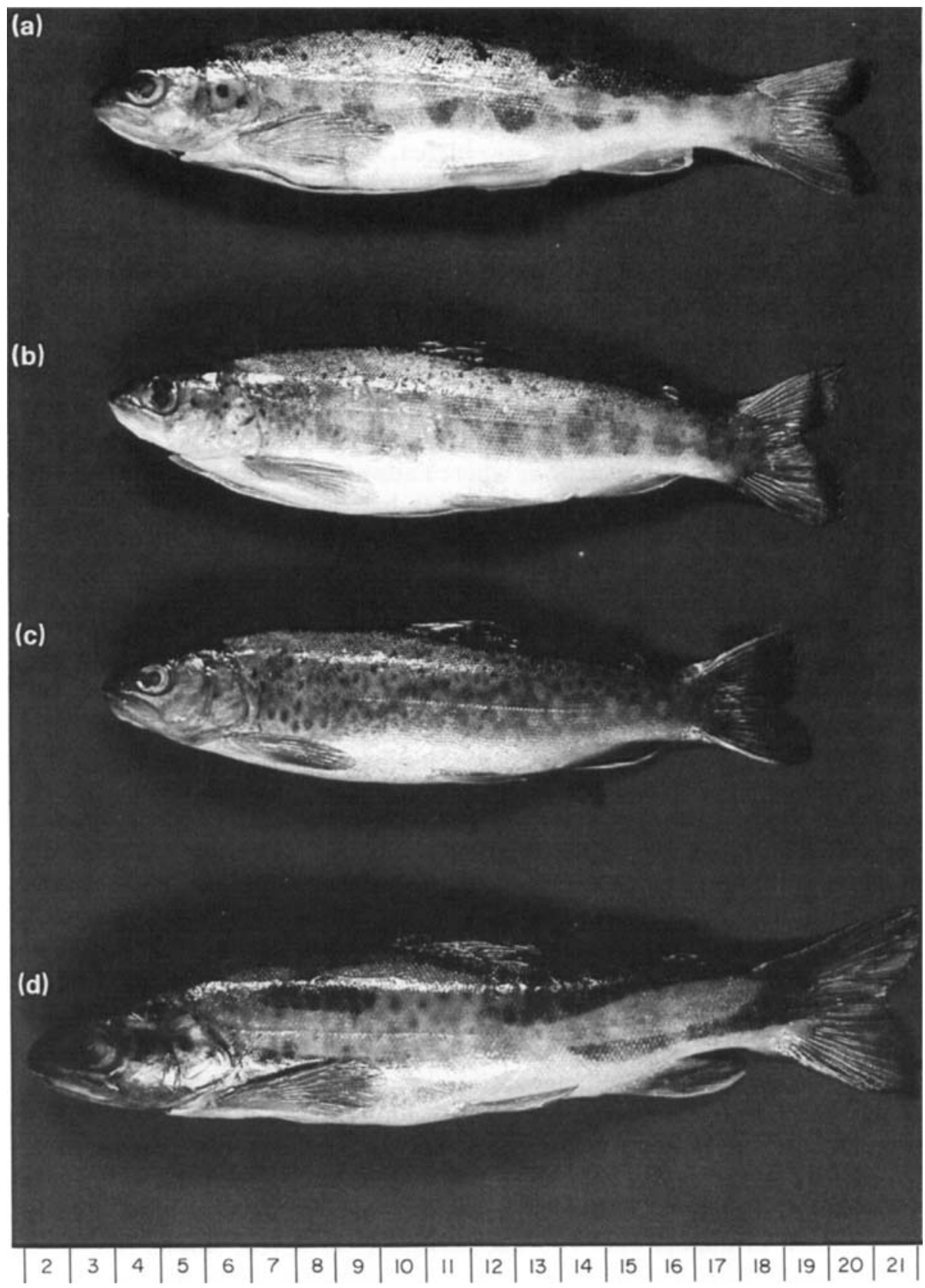

FIG. 2. Atlantic salmon, brown trout and natural hybrids from the river Ason: (a) Atlantic salmon parr, (b) salmon-like hybrid, (c) brown trout and (d) trout-like hybrid. The abnormal colour pattern of (d) is an artifact of handling.

$G=2 \cdot 16, P=0 \cdot 54)$. The overall rate of hybridization was $4 / 175$ or $2 \cdot 3 \%$. In the Ason, Deva and Sella rivers, significantly more brown trout than salmon were caught during electrofishing, while the reverse was true for the Pas (Table I). 


\section{DISCUSSION}

The frequency of Atlantic salmon and brown trout hybrids in Spanish rivers $(2.3 \%)$ is significantly higher $(G=6.91, P=0.009)$ than that observed in the British Isles $(0.3 \%$, Solomon \& Child, 1978$)$ and in Sweden $(\sim 0.1 \%$, Gunnar Ståhl, pers. comm., see Verspoor, 1988). It is also higher, but not significantly so $(G=2 \cdot 20$, $P=0.14)$, than levels in North America $(0 \cdot 8 \%$, Verspoor, 1988) where brown trout are an introduced species, and where hybridization might be expected to be unnaturally high (Hubbs, 1965)

The reported hybridization rates between Alantic salmon and brown trout are often conservative estimates, as the samples collected included only fish resembling one of the two parental species (Payne et al., 1972; Crozier, 1984; Verspoor, 1988; this study): since hybrids can resemble either salmon or trout (Fig. 2; Piggins, 1965; Solomon \& Child, 1978), an unknown proportion of hybrids will be classed as being the 'other' species and will not be sampled. True hybridization rates will also be underestimated in situations where natural populations of salmon and/or trout have been augmented by stocking with hatchery-reared fish, and these are included in the sample. While this does not apply to the Newfoundland populations examined by Verspoor (1988), it will to some extent be true for samples from Britain (Payne et al., 1972; Solomon \& Child, 1978) and Spain. Correcting for this is difficult but, based on genetic identification (E. Verspoor \& C. Garcia de Leaniz, unpubl. data), 29 of the salmon in our samples were introduced hatchery fish, raising the estimated rate of hybridization to $2 \cdot 8 \%$.

The apparently high frequency of hybrids in the Spanish rivers could be due to several factors. Estimates for Britain were based on samples of adult ' salmon ' and smolts (Solomon \& Child, 1978) which may yield low frequencies if some hybrids are non-migratory. This may account for some of the observed differences between Britain and North America but cannot explain the large difference between Spain and Sweden, and is unlikely to explain most of the difference between Spain and Britain. Even if $50 \%$ of hybrids migrate to sea, the hybridization frequency in Spain is still more than four times higher than in Britain, and over 20 times higher than in Sweden.

Several circumstances peculiar to Spanish rivers could potentially promote hybridization. In the summer, water temperatures can reach extreme values and periodic droughts coupled with increasing seasonal demand for water abstraction are known to result in isolated pools in which adult salmon and trout are effectively trapped (Garcia de Leaniz \& Martinez, 1988). Under these conditions, intercrossing may be favoured by forcing fish to spawn in reduced areas of the stream. Also, catches of salmon in Spanish rivers fluctuate greatly between years, and are composed of almost only two age classes: 1- or 2-year smolts returning as two-sea-winter salmon (Garcia de Leaniz \& Martinez, 1988; Martin Ventura, 1988). As a result, failures in only one year class (either in fresh water or at sea) will have a drastic effect on subsequent adult spawning, causing shortage of mates in some years. In 1982, for example, only three adult salmon were caught in the R. Ason, whereas the catch levels in the previous and following years were 54 and 70 salmon, respectively (Garcia de Leaniz \& Martinez, 1988).

The mating behaviour of sexually mature male parr (Jones \& King, 1952; Myers \& Hutchings, 1987) is thought to be less discriminating than that of adult salmon, so 
intercrossing may increase in situations where mature parr abound (Crozier, 1984; Verspoor, 1988). Early sexual maturation among salmon parr in Spanish rivers has been found to be exceptionally high, $43 \%$ of the males maturing as $0+$ and almost $100 \%$ among the older age classes (C. Garcia de Leaniz and A. Hawkins, in prep.). Under these conditions, and when the relative density of female adult salmon is low, interspecific crossing between male parr and female brown trout may increase.

Reproductive isolation may also decrease as a consequence of the introduction of foreign populations for stocking purposes (Vuorinen \& Piironen, 1984). Stocking with foreign salmon ova and fry is widespread in most rivers of northern Spain (Garcia de Leaniz \& Martinez, 1988). Indeed, examination of genetic differences between native and introduced salmon, and the genetic make-up of brown trout in Spanish rivers (E. Verspoors \& C. Garcia de Leaniz, unpubl. data), allow one of the four hybrids to be unequivocally identified as the progeny of a cross between an introduced salmon and a native brown trout.

The factors contributing to hybridization between Atlantic salmon and brown trout in the wild are likely to be complex and numerous. Further research is needed to determine if the disturbance of the populations or the extreme environmental conditions are the major reasons for high rates of hybridization in northern Spain, and to guide management programmes towards minimizing its occurrence. If this is not done the implications could be serious, as they have been in the case of hybridization of introduced rainbow trout with native cutthroat trout in North America (Benke, 1972).

The authors gratefully acknowledge the co-operation of J. J. Martinez Fernandez, Servicio de Montes, Caza y Conservacion de la Naturaleza, Consejeria de Ganaderia, Agricultura y Pesca de la Diputacion Regional de Cantabria, and of the Servicio de Conservacion de la Naturaleza, Consejeria de Agricultura y Pesca del Principado de Asturias, and thank A. D. Hawkins, W. M. Shearer, M. Suarez and J. A. Martin Ventura for helping in the collection of samples.

\section{References}

Benke, R. J. (1972). The systematics of salmonid fishes of recently glaciated lakes. J. Fish Res. Bd Can. 29, 639-671.

Beland, K. F., Roberts, F. L. \& Saunders, R. L. (1981). Evidence of Salmo salar $\times$ Salmo trutta hybridisation in a North American river. Can. J. Fish. Aquat. Sci. 38, 552-554.

Crozier, W. W. (1984). Electrophoretic identification and comparative examination of naturally occurring $\mathrm{F}$ hybrids between brown trout (Salmo trutta L.) and Atlantic salmon (Salmo salar L.). Comp. Biochem. Physiol. 78B, 785-790.

Garcia de Leaniz, C. \& Martinez, J. J. (1988). The Atlantic salmon in Spain with particular reference to Cantabria. In Atlantic Salmon: Planning for the Future (Proc. Third Int. Atlantic Salmon Symp., Biarritz, 21-23 October 1986) (D. Mills and D. Piggins, eds), pp. 179-209. London: Croom Helm.

Hubbs, C. (1965). Hybridisation between fish species in nature. Syst. Zool. 4, 1-20.

Jones, J. W. \& King, G. M. (1952). The spawning of the male salmon parr (Salmo salar Linn. juv.). Proc. Zool. Soc. 122, 615-619.

Martin Ventura, J. A. (1988). The Atlantic salmon in Asturias, Spain: analysis of catches, 1985-86. Inventory of juvenile densities. In Atlantic Salmon: Planning for the Future (Proc. Third Int. Atlantic. Salmon Symp., Biarritz, 21-23 October 1986) (D. Mills and D. Piggins eds), pp. 210-277. London: Croom Helm.

Myers, R. A. \& Hutchings, J. A. (1987). Mating of anadromous Atlantic salmon, Salmo salar L., with mature male parr. J. Fish Biol. 31, 143-146. 
Payne, R. H., Child, A. R. \& Forrest, A. (1972). The existence of natural hybrids between the European trout and the Atlantic salmon. J. Fish Biol. 4, 233-236.

Piggins, D. J. (1965). Salmon and sea trout hybrids. Ann. Rep. Salm. Res. Trust Ireland Inc. App. III, 27-36.

Sokal, R. R. \& Rohlf, F. J. (1981). Biometry. San Francisco: W. H. Freeman.

Solomon, D. J. \& Child, A. R. (1978). Identification of juvenile natural hybrids between Atlantic salmon (Salmo salar L.) and trout (Salmo trutta L.). J. Fish. Biol. 12, 499-501.

Verspoor, E. (1988). Widespread hybridization between native Atlantic salmon, Salmo salar, and introduced brown trout, S. trutta, in eastern Newfoundland. J. Fish Biol. 32, 327-334.

Vourinen, J. \& Piironen, J. (1984). Electrophoretic identification of Atlantic salmon (Salmo salar), brown trout (S. trutta), and their hybrids. Can.J. Fish. Aquat. Sci. 41, $1834-1837$. 